\title{
Drug utilization study in geriatric patients visiting medicine OPD in tertiary care hospital
}

\author{
Ujwala P. Gawali*, Salman H. Rizvi, Prashant S. Mishra
}

Department of Pharmacology, Dr Vaishampayan Memorial Government Medical College, Solapur, Maharashtra, India

Received: 20 January 2021

Accepted: 02 March 2021

*Correspondence:

Dr. Ujwala P. Gawali,

Email: ujwalagawali1963@gmail.com

Copyright: ( $)$ the author(s), publisher and licensee Medip Academy. This is an open-access article distributed under the terms of the Creative Commons Attribution Non-Commercial License, which permits unrestricted non-commercial use, distribution, and reproduction in any medium, provided the original work is properly cited.

\begin{abstract}
Background: Drug utilization study is of utmost importance in the elderly. The consumption of drug amongst elderly segment of society is maximum and many of them use at least three prescribed drugs, concurrently. One of the plausible explanation of usage of large number of medicines is prevalence of multi-morbidities as well as suffer from chronic and degenerative pathology amongst them along with the alteration of pharmacokinetics and pharmacodynamics of many drugs are altered with advanced age. Thus, the aim of this study was to assess current prescribing practices among physicians for geriatric patients in tertiary care hospital.

Methods: A prospective, observational and cross-sectional study was conducted in Department of Pharmacology in collaboration with Department of Medicine in a tertiary healthcare hospital. As per inclusion criteria, patients visiting Medicine outpatient department (OPD) from 01 October 2018 to 31 December 2018 were enrolled in the study.

Results: The average number of drugs per encounter was $4.1 .100 \%$ of the drugs were prescribed by their generic name and those prescribed from World Health Organization (WHO) list of essential medicines were 70.2\%. Analysis of polypharmacy showed maximum 11 and minimum 1 drug was prescribed. Overall analysis of the drugs showed, the most common route of administration was orally. Drugs acting on cardiovascular system (CVS), gastrointestinal system (GI) system, analgesics and anti-inflammatory drugs and vitamins and mineral supplements constitute the major bulk of drug prescribed.

Conclusions: In our study, though polypharmacy was found but it was necessary unavoidable, but was within the WHO standards of 1.6 to 4.8. Drugs acting on CVS and GI system were the most common drugs prescribed. Prescriptions with injections and steroids were less in the study population. All the drugs were prescribed by their generic name and most were present in the essential list of medicines.
\end{abstract}

Keywords: CVS, GI system, Medicine, Drug utilization study, Geriatric

\section{INTRODUCTION}

Drug utilization study is of utmost importance in the elderly. According to WHO, drug utilization research was defined as the marketing, distribution, prescription, and use of drugs in a society, with special emphasis on the resulting medical, social and economic consequences. ${ }^{1,2}$ The consumption of drug amongst elderly segment of society is maximum and many of them use at least three prescribed drugs, concurrently. ${ }^{3-5}$ One of the plausible explanation of usage of large number of medicines is prevalence of multi-morbidities as well as suffer from chronic and degenerative pathology amongst them along with the alteration of pharmacokinetics and pharmacodynamics of many drugs are altered with advanced age. ${ }^{6,7}$ Previous studies have revealed that because of exclusion of frail elderly from clinical trials, the knowledge about the efficacy and safety of many drugs is often sparse. ${ }^{6,7}$ It is evident from epidemiological studies that the elderly population is increasing rapidly still rational prescribing of medicines in elderly continues to 
present a major challenge. ${ }^{8}$ Inappropriate prescribing or use trends are common in elderly and to prevent this many guidelines and criteria like Beer's criteria have been used but still there is a need of improvement in this field. ${ }^{9}$

The most crucial phase of pharmacotherapy of any disease is its appropriate diagnosis followed by rational prescribing of drugs. Irrational polypharmacy accounts for $28 \%$ of adverse drug reactions and also stimulate inappropriate patient demand leading to reduced access and attendance rates due to medicine stock outs and loss of patient confidence in health. ${ }^{10}$ It has been estimated that $50 \%$ or more medicine expenditure is being wasted through irrational prescribing, dispensing and patient use of medicine. ${ }^{11}$

World Health Organization (WHO) convened a conference on "rational drug use" in Nairobi in 1985 defined rational drug use as follows: the rational use of drug requires that patients receive medications appropriate to their clinical needs, in doses that meet their own individual requirements for an adequate period and at the lowest cost to them and their community. ${ }^{12}$ Along with this, competent and qualified pharmacist should be trained for dispensing and for giving proper instruction to the patients on safe and effective usage of drugs. ${ }^{13}$

Rational medication prescribing dictates that the fewest medications be used achieve the therapeutic goals as determined by clinician and patients. Multiple medications not only add to the cost and complexity of therapeutic regimens, but also play patients at greater risk for adverse drug reactions and drug-drug interactions. ${ }^{14}$

Prescription pattern studies will identify problems before a drug is dispensed and will greatly improve patient care. ${ }^{15}$

Hence, the current study will evaluate the prescription pattern of geriatric medications and recent trends in geriatric polypharmacy at a tertiary health care centre.

The aim of the study was to assess and evaluate current prescribing pattern for geriatric patients visiting medicine OPD in tertiary care hospital.

The objectives were to analyze the demographic pattern of geriatric patients visiting medicine OPD, to analyse the distribution of drugs prescribed according to group of drugs, to evaluate the occurrence of polypharmacy, to analyse the distribution of drugs according to dosage forms and to calculate the percentage of drugs following guidelines of WHO prescription indicators.

\section{METHODS}

This prospective and observational study was carried out in department of pharmacology in collaboration with department of medicine of a tertiary healthcare teaching institute in Maharashtra.

\section{Study design}

It was a hospital based prospective, cross-sectional and observational study.

\section{Study period}

The study was conducted over a period of 3 months from 01 October 2018 to 31 December 2018 at Shri Chhatrapati Shivaji Maharaj Sarvopchar Rugnalay, Solapur, Maharashtra.

\section{Sampling}

A total of 360 prescriptions were selected.

\section{Inclusion criteria}

All patients of either sex and above the age of 60 years visiting medicine OPD.

\section{Exclusion criteria}

Patients below the age of 60 years, those unwilling to participate in the study and all IPD patients.

\section{Methodology}

The sampling frame was fixed as ten prescriptions/day, three days/week during the study period. In case of OPD holidays or non-fulfilment of target of ten prescriptions/day, the prescriptions of that day was done on next working day. Daily sampling must have at least one prescription of both genders. Patients' prescription records was used to collect data on most recent prescribed medication.

The following data was collected and analysed: demographic information i.e. age and sex, diagnosis, drugs categorized into different classes and dosage form, prevalence of polypharmacy, percentages of fixed-dose combinations (FDCs), and percentage of drugs following guidelines of WHO prescription indicators". ${ }^{11}$

\section{Ethical approval}

It was obtaining from the institutional ethics committee. Patients were given prior information.

\section{Statistical analysis}

Data was entered into Microsoft Excel, 2013. Descriptive statistics such as frequencies and percentages were calculated for categorical variables.

\section{RESULTS}

The present study was an observational study conducted in Department of Medicine of a tertiary care teaching hospital 
after obtaining permission from the institutional ethics committee (IEC) and Department of Medicine. In this study, prescription of 360 patients attending the OPD of Department of Medicine over a period of 3 months were assessed.

\section{Distribution of patients according to gender}

Out of the total 360, $198(55 \%)$ were males and $162(45 \%)$ were females (Table 1).

Table 1: Distribution according to gender.

\begin{tabular}{|lll|}
\hline Gender & No. & Percentage \\
\hline Male & 198 & 55 \\
\hline Female & 162 & 45 \\
\hline
\end{tabular}

\section{Distribution of patients according to age group}

In this study, patients were divided into four groups based on different age. Out of 360 patients $69(19.2 \%)$ were from 61-70 years followed by $129(35.8 \%)$ were from $71-80$ years, $84(23.3 \%)$ were from $81-90$ years and $78(21.7 \%)$ from $>91$ years respectively (Table 2 ).

Table 2: Distribution according to age group.

\begin{tabular}{|lll|}
\hline Age & No. & Percentage \\
\hline $\mathbf{6 1 - 7 0}$ & 69 & 19.2 \\
\hline $\mathbf{7 1 - 8 0}$ & 129 & 35.8 \\
\hline $\mathbf{8 1 - 9 0}$ & 84 & 23.3 \\
\hline$>\mathbf{9 1}$ & 78 & 21.7 \\
\hline
\end{tabular}

\section{Distribution of drugs according to group of drugs}

Out of the total 360 prescriptions, $24 \%$ were drugs acting on CVS, $17 \%$ were drugs acting on GI system, $14 \%$ were analgesics and anti-inflammatory drugs, $14 \%$ were vitamins and mineral supplements, $8 \%$ were drugs acting on endocrine system, $8 \%$ were drugs acting on respiratory system, $7 \%$ were antibiotics, $4 \%$ with drugs acting on CNS and $4 \%$ with others (Table 3 ).

Table 3: Distribution of patients according to group of drugs.

\begin{tabular}{|l|l|}
\hline Class & Percentage \\
\hline Drugs acting on CVS & 24 \\
\hline Drugs acting on GI system & 17 \\
\hline $\begin{array}{l}\text { Analgesics and anti-inflammatory } \\
\text { drugs }\end{array}$ & 14 \\
\hline Vitamins and mineral supplements & 14 \\
\hline Drugs acting on endocrine system & 8 \\
\hline Drugs acting on respiratory system & 8 \\
\hline Antibiotics & 7 \\
\hline Drugs acting on CNS & 4 \\
\hline Others & 4 \\
\hline
\end{tabular}

\section{Number of drugs prescribed per prescription}

Number of drugs per prescription varied from 1 to 11 with average of 4.1 drugs per prescription. Most of them, $65 \%$ had 4 to 5 drugs, $14.1 \%$ having 2 to 3 drugs (Table 4 ).

Table 4: Distribution of drugs prescribed per prescription.

\begin{tabular}{|lll|}
\hline $\begin{array}{l}\text { No. of drugs } \\
\text { prescribed }\end{array}$ & No of prescription & Percentage \\
\hline $\mathbf{1}$ & 3 & 0.8 \\
\hline $\mathbf{2}$ & 51 & 14.1 \\
\hline $\mathbf{3}$ & 66 & 18.3 \\
\hline $\mathbf{4}$ & 105 & 29.1 \\
\hline $\mathbf{5}$ & 63 & 17.5 \\
\hline $\mathbf{6}$ & 39 & 10.8 \\
\hline $\mathbf{7}$ & 27 & 7.5 \\
\hline $\mathbf{8}$ & 3 & 0.8 \\
\hline $\mathbf{1 1}$ & 3 & 0.8 \\
\hline
\end{tabular}

\section{Distribution of drugs according to dosage forms}

Out of all the drugs prescribed in 360 prescriptions, $74 \%$ were tablets, $18 \%$ were capsules, $3.2 \%$ were syrups, $2.7 \%$ were injectables and $2.1 \%$ were creams (Table 5).

Table 5: Distribution drugs according to dosage form.

\begin{tabular}{|lll|}
\hline Dosage form & No. & Percentage \\
\hline Tablets & 1112 & 74 \\
\hline Capsules & 270 & 18 \\
\hline Syrups & 49 & 3.2 \\
\hline Injectables & 40 & 2.7 \\
\hline Creams & 32 & 2.1 \\
\hline
\end{tabular}

Table 6: WHO core drug use indicators - prescribing indicators. $^{15}$

\begin{tabular}{|l|l|}
\hline WHO core drug use indicators & $\begin{array}{l}\text { Number/per } \\
\text { centage }\end{array}$ \\
\hline $\begin{array}{l}\text { Average number of drugs per } \\
\text { prescription }\end{array}$ & 4.1 \\
$\begin{array}{l}\text { Drugs prescribed by generic name } \\
(\%)\end{array}$ & 100 \\
\hline $\begin{array}{l}\text { Encounters with an antibiotic } \\
\text { prescribed (\%) }\end{array}$ & 7 \\
\hline $\begin{array}{l}\text { Encounters with a steroid prescribed } \\
(\%)\end{array}$ & 0 \\
\hline $\begin{array}{l}\text { Encounters with an injection } \\
\text { prescribed (\%) }\end{array}$ & 2.7 \\
\hline $\begin{array}{l}\text { Prescribed drugs featuring in WHO } \\
\text { essential drugs list (\%) }\end{array}$ & 70.2 \\
\hline \begin{tabular}{l} 
Drugs prescribed by FDCs (\%) \\
\hline
\end{tabular} & 8.4 \\
\hline
\end{tabular}

\section{WHO/INRUD rational drug-use indicators}

The drug usage was assessed as per WHO core drug use indicators, prescribing indicators revealed that out of the 
total drugs prescribed, $100 \%$ were prescribed by generic names and about $70.2 \%$ of the drugs were prescribed from the WHO essential drug list. Overall, the average number of drugs per encounter was 4.1. The proportions of encounters with at least one antibiotic prescribed was $7 \%$. Present study shows that total of $8.4 \%$ drugs prescribed as fixed drug combination. $0 \%$ of the total prescriptions encountered with a steroid prescribed while injections were found to be prescribed in $2.7 \%$ encounters. $70.2 \%$ drugs prescribed were WHO essential drug list 2017 (Table 6). ${ }^{16}$

\section{DISCUSSION}

The present study was an observational study conducted in Department of Medicine of a tertiary care teaching hospital after obtaining permission from the institutional ethics committee (IEC) and Department of Medicine. In this study, prescription of 360 patients attending the OPD of Department of Medicine over a period of 3 months were assessed.

In the present study, males, $55 \%$ were more than females, $45 \%$, which was similar to studies conducted by both Nishandar et al, males $61 \%$ and females 39\%, and Jadhav et al, males $61.3 \%$ and females $58.7 \% .^{17,18}$

In the present study, more than $63 \%$ of the patients belonged to the age group of 61 to 70 years followed by $25 \%$ in the age group of 71 to 80 years and $12 \%$ in the age group of more than 80 year, which was similar to the study conducted by both Nishandar et al and Goudanavar et al. ${ }^{17,19}$

The present study findings suggested that drugs acting on CVS was the most common class of drugs prescribed, which was similar to the study conducted by both Nishandar et al and Jadhav et al. ${ }^{17,18}$

The second most common class of drugs was drugs acting on GI system followed by analgesics and antiinflammatory drugs, which was similar to study conducted by Jadhav et al but different to that by Nishandar et al, having analgesics and NSAIDs being second most common followed by drugs acting on gastrointestinal system. ${ }^{17,18}$

The average number of drugs/prescription in current study were 4.1 drugs, which was similar to studies conducted by Nishandar et al (3.4) and Jadhav et al (4.3). ${ }^{17,18}$

The current study findings suggested that $74 \%$ of the drugs were prescribed in the form of tablets, $18 \%$ were prescribed in the form of capsules, $3.2 \%$ was in the form of syrups, $2.7 \%$ was in the form of injectables and $2.1 \%$ were in the form of creams.

Under WHO core drug use indicators, in the present study, $100 \%$ of the drugs were prescribed by generic names, which was $61.7 \%$ in study conducted by Nishandar et al and just $26.4 \%$ in the study by Jadhav et al. ${ }^{12,17,18}$ Whereas only $7 \%$ of the encounters had an antibiotic prescribed in present study, compared to $33.5 \%$ in study by Nishandar et al and $7.5 \%$ by Jadhav et al. ${ }^{17,18}$ Percentage of encounters having at least one steroid prescribed were $0 \%$ in the present study. Percentage of encounters having at least one injectable prescribed were $2.7 \%$ in present study, was $0.15 \%$ in study conducted by Nishandar et al and $3.5 \%$ in study conducted by Jadhav et al. ${ }^{17,18}$ Percentage of prescribed drugs featuring in WHO essential drugs list were $70.2 \%$ in present study (2017), was $83.2 \%$ in study conducted by Nishandar et al (2015) and $86.3 \%$ in study by Jadhav et al (2015). ${ }^{12,17,18}$ Percentage of drugs prescribed by FDCs were $8.4 \%$ in current study, was $1.1 \%$ in study conducted by Nishandar et al and was $13.2 \%$ in the study by Jadhav et al. ${ }^{17,18}$

\section{Limitations}

There exists some limitation to our study. The study was conducted in a tertiary care hospital located in urban area which cannot reflect the health care facilities available to all health centres particularly in the rural areas. This research was limited by size and site of the study population, a larger population size could give a better result and more reliable outcomes which could be generalize for the entire community.

\section{CONCLUSION}

Increasing prescribing in geriatric has necessitated assessment of their rational usage. In our study, though polypharmacy was found but it was necessary and unavoidable, but was within the WHO standards of 1.6 to 4.8. Drugs acting on CVS, drugs acting on GI system and analgesics and anti-inflammatory drugs were the most common drugs prescribed in our study population and were in line to the common problems faced by the geriatric population. Prescriptions encountered with injections and steroids were less in the study population, this is an encouraging sign and need to be encouraged. All the drugs were prescribed by their generic name and most were present in the essential list of medicines, which is an encouraging sign. Promoting 'WHO rational drug use policy' is recommended for effective healthcare management.

Funding: No funding sources

Conflict of interest: None declared

Ethical approval: The study was approved by the Institutional Ethics Committee

\section{REFERENCES}

1. Shalini S, Ravichandran V, Mohanty BK. Drug utilization studies - an overview. Intern J Pharma Sci Nanotech. 2010;3(1):803-10.

2. Gama H. Drug utilization studies. Arquivos De Medicina. 2008;22;(2):69-74.

3. Guaraldo L, Cano FG, Damasceno GS. Inappropriate medication use among the elderly: a systematic review 
of administrative databases. Biomed Central Geriatr. 2011;11:79.

4. Kaufman DW, Kelly JP, Rosenberg L, Anderson TE, Mitchell AA. Recent patterns of medication use in the ambulatory adult population of the United States: the Slone survey. JAMA. 2002;287(3):337-44.

5. Barat I, Andreasen F, Damsgaard EMS: The consumption of drugs by 75-year-old individuals living in their own homes. Eur J Clin Pharmacol. 2000;56(6-7):5019.

6. Straand J, Rokstad K. Elderly patients in general practice: diagnoses, drugs and inappropriate prescriptions. A report from the Møre and Romsdal Prescription Study. Family Practice. 1999;16:380-8.

7. Bugeja G, Kumar A, Banerjee Arup K. Exclusion of elderly people from clinical research: a descriptive study of published reports. Br Med J. 1997;315:1059.

8. Zaveri HG, Mansuri SM, Patel VJ. Use of potentially inappropriate medicines in elderly: A prospective study in medicine out-patient department of a tertiary care teaching hospital. Indian $\mathrm{J}$ Pharmacol. 2010;42(2):95-8.

9. Fadare JO, Agboola SM, Opeke OA. Prescription pattern and prevalence of potentially inappropriate medications among elderly patients in a Nigerian rural tertiary hospital. Ther Clin Risk Manag. 2013;6:11520.

10. Lenjisa JL, Fereja TH. A Retrospective Analysis of Prescribing Practice Based on WHO Prescribing Indicators at Four Selected Hospitals of West Ethiopia: Policy Implication. East Central Afr J Pharm Sci. 2013;16:69-74.

11. The Rational use of drugs, report on the conference of experts Nairobi sponsored by WHO Geneva. 1985. Available

at: https://apps.who.int/iris/handle/10665/37174.

Accessed on 02 December 2020.

12. Alam K, Mishra P, Prabhu M, Shankar PR, Plalain S, Bhandari RB, et al. A study on rational drug prescribing and dispensing in outpatients in a tertiary care teaching hospital of western Nepal. Kathmandu University Med J. 2006;4(4):436-43.

13. Good CB. Polypharmacy in elderly patients with diabetes. Diabetes Spectrum. 2002;15(4):240-8.

14. Salman S, Ismail M, Awan NR, Anees M. Patterns of prescription writing in psychiatric clinics. J Postgrad Med Inst. 2013;27(3):290-6.

15. World Health Organization. Fact sheet: WHO core drug use indicators. 2017. Available at http://apps.who.int/medicinedocs/en/d/Js2289e/3.htm 1. Accessed on: 22 March 2019.

16. WHO Model Lists of Essential Medicines. 2019. Available at: https://www.who.int/medicines/publications/essential medicines/en/. Accessed on: 22 March 2019.

17. Nishandar TB, Kale AS, Pise HN. Drug Utilization Pattern In Geriatric Patients Attending Out Patient Department At Rural Tertiary Care Hospital In Maharashtra. Asian J Pharm Clin Res. 2017;10(2):314-6.

18. Jadhav RR, Jadhav AD, Padwal SL, Kale AS, Pise HN. Drug utilization pattern in geriatric out patient in tertiary care hospital. Int J Basic Clin Pharmacol. 2017;6:2078-81.

19. Goudanavar P, Keerthi Y, John SE, Jacob J, Krishna MSR. A Prospective Study on Medication Prescribing Pattern for Geriatric Patients in A Tertiary Care Teaching Hospital. Asian J Biomed Pharm Sci. 2016;6(56):23-7.

Cite this article as: Gawali UP, Rizvi SH, Mishra PS. Drug utilization study in geriatric patients visiting medicine OPD in tertiary care hospital. Int $\mathbf{J}$ Basic Clin Pharmacol 2021;10:386-90. 